\title{
Research on the Plight and Way out of Advertising Network
}

\author{
Wei Huang ${ }^{1}$ \\ ${ }^{1}$ Polytechnic Institute of Jiangxi Science \& Technology Normal University, Nanchang Jiangxi \\ 330100 , China \\ 346591653@163.com
}

KEYWORDS: Advertising Network, Plight, Way out

\begin{abstract}
With the continuous development of network technology, e-commerce is also showing a good development trend, more and more business people and companies began to focus on online advertising. In recent years, online advertising industry in the process of rapid development, there has also been a lot of problems. In this paper, for the difficulties faced by the industry Network analysis and reasonable treatment measures, hoping to further promote the rapid development of the advertising network industry.
\end{abstract}

\section{Introduction}

In recent years, online advertising is growing at the birth of the Internet situation, we can say there is network advertising conforms to the trend of the times, it is highly targeted, interactive and diverse forms, from the birth of the future of online advertising, position in the advertising market in a gradual increase [1]. Especially in the situation of computer technology and the rapid development of the Internet, online advertising achieved relatively good results in the advertising market. However, the ad network has now developed into trouble, how to effectively deal with the plight faced by the ad network, thereby promoting the development of the networking industry has become the focus of public attention.

\section{The Current Difficulties of Advertising Network}

In China, online advertising in a whole new form of media advertising appears in people's vision, from birth after being a lot of attention. Because the ad network and the conventional media advertising has many advantages compared with each other, regardless of ad serving providers, producers or advertising, ad networks are given a great deal of recognition and support. However, the current ad networks in development, but because a lot of problems in trouble, the following article is to analyze the problems for the current network.

\section{A. Internet Advertising Ideas is too Far Behind}

After making out online advertising needs for the majority of consumers, however, belongs to a new online advertising media advertising, many consumers lack awareness of online advertising, and therefore have psychological conflict [2]. On the other hand, online advertising has been served, although producers and distributors of support and recognition, but the ideas many consumers stay on the level of conventional media advertising, and online advertising together with the producers is difficult to guarantee advertising effectiveness, these are caused by many consumers cannot accept the current online advertising reasons. 


\section{B. Defects of Network Facilities.}

In recent years, although the network technology has been rapid development, gradually penetrated into people's lives and work, but many of the network settings screen name applied there are many problems, such as: poor stability, fidelity function information poor, and speed is too slow, which means that users need to invest more time to wait for the download process of online advertising, so in real life there are few users do so. In addition, network software and hardware facilities prone to damage or lack of coordination, such as: the fusion of image and sound effect is not ideal, because the sound software and hardware facilities damaged, causing the closure or the image cannot be played, which issues are to some extent affect the effectiveness of online advertising.

\section{Lack of Professional Talents.}

Time online advertising in China's development is relatively short, and therefore, there is no sound of online advertising online advertising marketing and technical personnel and personnel training education system, both from the technical and marketing concepts and compared with some developed countries, there are certain distance, and staff many practitioners lack of online advertising experience design, which makes the role and value of online advertising are not fully reflected.

\section{Lack of Relevant Laws and Regulations.}

At this stage, our country has not developed laws and regulations of online advertising management, are still used in many parts of the government in 1995 promulgated the "Advertising Law", but, "Advertising Law" in the face of online advertising in the development of many of the problems could not have been reasonably be handled [3]. In this case, the online advertising industry's pricing system and competition system has produced a great deal of confusion. In addition, some business people and businesses for their own interests, publishing false information on online advertising, which affected the online advertising image in people's minds of the masses.

\section{Reasonable Countermeasures}

\section{A. Innovative Online Advertising Ideas.}

In the fierce competition in the online advertising market, advertising mainly want consumers to be able to accept online advertising, we should proceed from the concept of change in consumer thinking. First, the main advertising the role and value of online advertising to understand and grasp the ideas to change the consumer through a variety of reasonable means; Secondly, online advertising creative design process to seize this feature, use creative online advertising to attract the attention of consumers, as well as insight into the needs of the organization team of consumers, provide timely and effective advertising for their information; and finally, advertisers should also be large and conventional media or more well-known enterprise cooperation, the use of these companies brand in the market, so that more consumers understand online advertising [4]. Consumers really understand and recognize the role and value of online advertising only after the initiative to accept online advertising.

\section{B. Improve the Construction of Network Infrastructure.}

Online advertising network as a delivery vehicle is very important, therefore, to promote the development of online advertising industry should improve the network infrastructure deficiencies, we propose the following recommendations for the deficiencies of the current network infrastructure aspects: first relevant government departments should develop a professional research 
team constantly on network technology research and exploration, and to perfect for the current network infrastructure defects, thereby improving the overall quality of the network, the network can move high-speed, low-cost or direction does not charge development. The second, related businesses should create a lot of larger capacity network, and the network is currently being used to upgrade to better meet the needs of all aspects of online advertising. Third, the development of network technology for the late start of the phenomenon, should continue to learn the international network technology rapid development of technology and experience the country, thus contributing to the construction of our network infrastructure.

\section{Reasonable Training System.}

Online advertising online advertising marketing and technical personnel and personnel directly affect the future development of online advertising, therefore, the government should be reasonably sound personnel training system. First, advertising majors in colleges and universities are currently training, the government can recruit some higher network advertising professional competence of lecturers from international to be taught to improve their mastery of computers, marketing and dissemination of knowledge, so that advertising professionals students after graduation to meet the requirements of social development; Secondly, online advertising manufacturers can recruit some computer technicians, and then train them related disciplines, such as: marketing, graphic design, so that these computer technicians to participate Internet advertising in the production process; and finally, online advertising manufacturers should put the current online advertising and online advertising design talent in the form of marketing professionals organize activities together, so as to promote the exchange of personnel between, because every human ideas and concepts they are not the same, through in-depth exchanges, not only to enrich their work experience, but also to expand their horizons, to make online advertising design and sales personnel to play a greater role in future work. All in all, the purpose of a sound personnel training system, is to deliver more professionals to our future network society.

\section{Improve the Laws and Regulations of Online Advertising Management}

Any industry you want to get long-term development, are inseparable from laws and regulations, the online advertising industry, too [5]. Therefore, the relevant government departments as the main regulation of the market economy, should improve laws and regulations of online advertising management. First, it should be for the current network ads appear in the development of problem formulation, the government departments concerned should organize a professional team to the advertising market on the cause of the problem in-depth investigations, so as to formulate relevant laws and regulations; secondly, in view of lack of network scientific credentials advertising management, government laws and regulations in developed countries can learn from online advertising industry, combined with the development of China's national conditions, first practiced in some areas of China in the future to develop in the future in line with China's actual circumstances were implemented. Finally, with the development of online advertising industry, many new problems will inevitably arise, the government should do to supplement and revise work laws and regulations to improve protection for the development of China's online advertising industry.

\section{Conclusion}

In summary, the situation in recent years in computer technology and the rapid development of the Internet, online advertising industry has been relatively good development, but the development of online advertising has now caught in a dilemma, should be from the innovative concept of online 
advertising ideas; improve the construction of network infrastructure; reasonably sound personnel training system; and laws and regulations and improve the management of online advertising in these areas starting, thus promoting the rapid development of China's online advertising industry.

\section{REFERENCE:}

[1] The actual situation Jie Zhong University Computer Basic Teaching and Coping Strategies [J] Wind Science and Technology, 2015,23: 247.

[2] Wu Guang-Heng legal issues of unfair competition under the online advertising environment and countermeasures [J] Theory Monthly, 2012,06: 86-90.

[3] Shao Guosong online advertising control problems and countermeasures - Comment on "Advertising Law" was first modified [J] JAC Forum, 2015,04: 79-83 + 193.

[4] Wang Xiaoyu Analysis Network advertisements in the development problems and countermeasures [J] brand (second half), 2015,09: 70.

[5] Meng Xiangmei online advertising supervision and management of problem analysis and countermeasures [J] Chinese market, 2010,41: 102-103. 